\title{
EDITORIAL
}

\section{Drug history and remote exposure to drugs. A cause of lung disease?}

\author{
P. Camus
}

In this issue of the European Respiratory Journal, HUBBARD et al. [1] present the results of their study relating a history of exposure to antidepressant drugs with the development of "idiopathic" pulmonary fibrosis (IPF). In a cohort of well-defined IPF patients, they reported on a modest positive effect of prior exposure to antidepressants as a whole on the likelihood of developing pulmonary fibrosis. Only for amitriptyline, however, was the likelihood somewhat higher and statistically significant. According to these authors, reverse causation (i.e. the fact that the psychological strain of IPF required antidepressants, instead of these drugs causing the disease) may have played a role. It is of note that their earlier findings of an increased risk of pulmonary fibrosis associated with a history of exposure to imipramine or dothiepin [2] were not reproduced in this current study. Accordingly, they concluded that recent exposure to antidepressant drugs is unlikely to be associated with or cause pulmonary fibrosis. Likewise, they have reported formerly that exposure to $\beta$-blockers, anticonvulsants, antibiotics or nonsteroidal anti-inflammatory drugs is also unlikely to increase the risk of pulmonary fibrosis [2]. These studies on the possible role of exposure to drugs form part of other elegant studies by this group that are directed at the elucidation of what may cause IPF [2-5].

HUBBARD et al. [1] were aware of and even discussed, several weaknesses inherent to their study. To the knowledge of the present author, there was no control for ethnicity, socioeconomic status or presence of aerocontaminants in the home. More importantly, there was no control for occupation. These potential confounders may independently have influenced either the likelihood of developing pulmonary fibrosis (e.g. dusty environments $[6,7])$ or, conceivably also, the need for anti-depressant therapy. Also, no data were available regarding current or remote exposure to any of the thirty, or so, drugs other than antidepressants that are already known possibly to cause pulmonary fibrosis [8]. This is of importance as, for drugs such as amiodarone, chemotherapeutic agents or nitrofurantoin, the likelihood of developing pulmonary fibrosis is substantial. Conversely, in order to rule out reverse causation, the prescription of furosemide was used as a marker of IPF severity [1]. Indeed, furosemide was prescribed with increasing frequency, as a function of time, in patients with IPF, but a

Correspondence: Dept of Pulmonary Disease and Intensive Care, University Medical Centre at Dijon and Université de Bourgogne, Box 1542, 21034 Dijon, France. Fax: 33380293251. cause and effect relationship remains to be established. It is of note that odds ratios for furosemide exposure were consistently $>2$ (i.e. greater than the odd ratios for any of the antidepressants studied), in the 4 yrs preceding diagnosis of IPF. This even raises the possibility that furosemide may also cause IPF.

With these limitations in mind, however, the study of HUBBARD et al. [1] is of great importance in several respects regarding drug-induced respiratory disease, on the one hand, and the elucidation of possible causes of chronic unexplained interstitial lung disease, on the other. To the present author, the terms "cryptogenic" or "idiopathic" in cryptogenic fibrosing alveolitis or IPF (used interchangeably) reflect more the current inability to identify the underlying cause(s) of the disease than the real absence of cause(s) for it. Therefore, the varied attempts by HUBBARD and coworkers $[1,2,6]$ to elucidate possible inciting agents underlying apparently "idiopathic" pulmonary fibrosis should be complimented and encouraged.

To date, it has been relatively easy for pulmonologists to associate respiratory disease with current exposure to drugs, mainly because there has been close temporal association between the two events. Indeed, this is true of the vast majority of case reports on drug-induced respiratory diseases in the literature [8]. It is of note that, although the time to onset of the pulmonary adverse effect may vary greatly, from minutes for drug-induced bronchospasm/anaphylaxis $[9,10]$ to many years for amiodarone pneumonitis [11], the vast majority of patients were still on the drug at the time the adverse reaction developed. A further argument in favour of drugs as a cause is that, especially in patients with acute/subacute changes (e.g. subacute cellular (nonspecific) interstitial pneumonias, pulmonary oedema or pleural effusions), cessation of exposure to the offending drug leads to definite improvement or resolution of the respiratory abnormalities.

In contrast, few studies have insisted that adverse drug reactions in the lung can develop months to years after cessation of exposure to the drug [12-15]. Significant and illustrative clinical/radiographic patterns include: pneumonitis/fibrosis induced by thoracic $[16,17]$, cranial [18] or infused radiation therapy [19]; pneumonitis/fibrosis induced by the chemotherapeutic agents cyclophosphamide or nitrosoureas [20-23], or amiodaone [14]; pulmonary fibrosis in young adults who had received nitrosoureas for brain tumours in childhood [24]; pulmonary vascular disease and hypertension due to the intake of older [25] or more recent anorectics [15, 26-28]; 
irreversible bronchiolitis obliterans due to repeated intake of dietary Asian shrub leaves [29]; or pleural fibrosis due to ergoline compounds [30].

All these latter patterns developed long after cessation of exposure to the inciting agent, and are predominantly fibrotic and irreversible, as opposed to the reversible inflammatory changes mentioned above. Amiodarone is a notable exception, in that the drug may induce reversible pneumonitis or other adverse effects, weeks to a few months after cessation of exposure [14, 31, 32]. The very long retention time profile of that drug in lung tissues is probably an explanation [33]. In this connection, several antidepressants are also sequestered in lung tissues of rodents and humans [34], as also pointed out by HuBBARD et al. [1]. Whether chronic lung diseases such as IPF can be induced by the prolonged storage of excessive quantities of drug in the lung currently remains unknown. It should be noted, however, that, for two approximately equally sequestered drugs (namely amiodarone, and imipramine), the pulmonary toxicity profile is very different $[35,36]$. This tends to suggest that storage of drugs in the lung is neither the prerequisite nor the only determinant of pulmonary toxicity.

As exemplified above, the fact that pulmonary sequelae of delayed onset may follow exposure to drug or radiation therapy by many years is in keeping with the rationale of the study of HuBBARD et al. [1]. This may fuel further research in that area, especially with longer periods of observation and examination of the possible role of other drugs. A number of questions remain unanswered. 1) What is the recent drug history (e.g. which drugs have been given and/or stopped within the last year) of patients with clinical patterns such as bronchiolitis obliterans organizing pneumonia, accelerated interstitial lung disease, unexplained adult respiratory distress syndrome or sarcoidosis? Observational case histories indeed suggest that amiodarone [37-39], antibiotics [40], antirheumatic agents [41], interferons [42, 43] or statins [44] may cause such patterns of involvement, but firm epidemiological data are lacking. Similar reasoning applies to subsets of oncology patients treated with several chemotherapeutic agents (notably busulphan) who develop the so-called "idiopathic pulmonary syndrome", a form of protracted and severe nonspecific chronic fibrosing interstitial pneumonia $[23,45,46]$. The exact role of the various drugs and their association or sequence of use all remain to be clarified. 2) What is the exact remote drug history (e.g. in the last $20 \mathrm{yrs}$ ) of patients with IPF, or with other forms of chronic respiratory fibrosis (e.g. lupus erythematosus with pleuropulmonary involvement, bronchiolitis obliterans, chronic pulmonary hypertension or pleural fibrosis)? Careful examination of the drug history of a cohort of patients with IPF, as in the study of HuBBARD et al. [1], or with any of the chronic aforementioned patterns of involvement is required, with, initially, particular attention to the commonly fibrogenic drugs amiodarone, nitrofurantoin or chemotherapeutic agents [8]. It is necessary to examine drug prescription over long periods of time as very remote exposure to a toxicant drug may conceivably lead to fibrosis of the lungs many years later. It should also be emphasized that the number of drugs known to be capable of causing respiratory problems has considerably increased with time. The author's continuously updated Pneumotox $(\mathbb{R})$ database currently details 318 causative drugs, in comparison with 204 in 1997 [47]. Thus drugs with currently unrecognized fibrogenic potential may have to be screened in the future.

The work of HUBBARD et al. [1] raises other questions in addition to these. 1) Are there differences in pulmonary susceptibility among different ethnic groups, as already suggested for other drugs [48, 49]? 2) Are medicinal herbs really harmless to the lung? Reports and concerns regarding these compounds have recently emerged [29, $50-55]$, and the present author is of the opinion that a history of herb intake/exposure should be obtained exactly as is done for drugs. 3) Since the myocardium [5659] and heart valves [60-63] may be damaged by drugs, drug history taking may also be of relevance in the cardiology field regarding patients with "idiopathic" cardiomyopathies.

To conclude, the idea behind the study of HuBBARD et al. [1], is likely to change conceptual views on iatrogenic lung disease. Indeed, physicians are well aware that the drugs they use daily may cause lung disease during the time they are given. They are also aware that some drugs may cause fibrosing alveolitis/pulmonary fibrosis during the prescription period, or relatively soon thereafter. If, in addition, some drugs can trigger "cryptogenic" fibrosing alveolitis/"idiopathic" pulmonary fibrosis, to be discovered many years later, then it would be extremely useful to know which drugs can do so, and the duration of exposure or drug associations that may put patients at risk, in order to formulate preventive and safety guidelines early during life. The cohort followed by British general practitioners and by HuBBARD et al. [1] may help solve these questions. Then and only then will it be possible to formulate pathophysiological questions aimed at elucidating additional risk factors, be they related to ethnicity, pharmacogenetics or the eminently variable pulmonary inflammatory/immune response to toxicants $[64,65]$.

\footnotetext{
Acknowledgements. The author would like to acknowledge the invaluable, refined and sophisticated impetus of C. Sartini.
}

\section{References}

1. Hubbard R, Venn A, Britton J. Exposure to antidepressants and the risk of cryptogenic fibrosing alveolitis: a case-control study. Eur Respir J 2000; 16: 409-413.

2. Hubbard R, Venn A, Smith C, Cooper M, Johnston I, Britton J. Exposure to commonly prescribed drugs and the etiology of cryptogenic fibrosing alveolitis. $\mathrm{Am} \mathrm{J}$ Respir Crit Care Med 1998; 157: 743-747.

3. Hubbard R, Johnston I, Coultas DB, Britton J. Mortality rates from cryptogenic fibrosing alveolitis in seven countries. Thorax 1996; 51: 711-716.

4. Hubbard R, Johnston I, Britton J. Survival in patients with cryptogenic fibrosing alveolitis: a population-based cohort study. Chest 1998; 113: 396-400.

5. Hubbard R, Venn A, Lewis S, Britton J. Lung cancer and cryptogenic fibrosing alveolitis - A population-based cohort study. Am J Respir Crit Care Med 2000; 161: 5-8.

6. Hubbard R, Lewis S, Richards K, Johnston I, Britton J. Occupational exposure to metal or wood dust and aetiology of cryptogenic fibrosing alveolitis. Lancet 1996; 347: 284-289. 
7. Chan-Yeung M, Müller NL. Cryptogenic fibrosing alveolitis. Lancet 1997; 350: 651-656.

8. The drug-induced lung diseases Website. www.pneumotox.com Foucher P, Camus P, and the GEPPI Producers. Last update: July 2000.

9. Trottier M, Vaillancourt R. Drug-induced asthma. Can Pharm J 1998; 131: 30-37.

10. Schuster C, Reinhart WH, Hartmann K, Kuhn M. Angioödem unter ACE-Hemmern and Angiotensin-IIreceptor-Antagonisten: Analyse von 98 Fällen. Schweiz Med Wochenschr 1999; 129: 362-369.

11. Kanji Z, Sunderji R, Gin K. Amiodarone-induced pulmonary toxicity. Pharmacotherapy 1999; 19: 1463-1466.

12. de Bandt M, Rat AC, Palazzo E, Kahn M-F. Delayed methotrexate pneumonitis. J Rheumatol 1992; 18: 1943.

13. Willenbacher W, Mumm A, Bartsch HH. Late pulmonary toxicity of bleomycin. J Clin Oncol 1998; 16: 3205.

14. Wilhelm JM, Thannberger P, Derragui A, Ruxer S, Saraceni O, Kieffer P. Interstitial pneumonia 2 months after discontinuing amiodarone. Presse Med 1999; 28 : 2040.

15. Hagiwara M, Tsuchida A, Hyakkoku M, et al. Delayed onset of pulmonary hypertension associated with an appetite suppressant, mazindol - A case report. Jpn Circulation J 2000; 64: 218-221.

16. Morgan GW, Freeman AP, McLean RS, Jarvie BH, Giles RW. Late cardiac, thyroid, and pulmonary sequelae of mantle radiotherapy for Hodgkin's disease. Int $J$ Radiation Oncol Biol Phys 1985; 11: 1925-1931.

17. Villani F, Demaria P, Bonfante V, et al. Late pulmonary toxicity after treatment for Hodgkin's disease. Anticancer Res 1997; 17: 4739-4742.

18. Jakacki RI, Schramm CM, Donahue BR, Haas F, Allen JC. Restrictive lung disease following treatment for malignant brain tumors: a potential late effect of craniospinal irradiation. J Clin Oncol 1995; 13: 14781485.

19. Lin M. Radiation pneumonitis caused by yttrium-90 microspheres: radiologic findings. Am $J$ Roentgenol 1994; 162: 1300-1302.

20. Limper AH, McDonald JA. Delayed pulmonary fibrosis after nitrosourea therapy. $N$ Engl J Med 1990; 323: 407409.

21. Hansen SW. Late-effect after treatment for germ-cell cancer with cisplatin, vinblastine, and bleomycin. Dan Med Bull 1992; 39: 391-399.

22. Malik SW, Myers JL, DeRemee RA, Specks U. Lung toxicity associated with cyclophosphamide use. Two distinct patterns. Am J Respir Crit Care Med 1996; 154: 1851-1856.

23. Wilczynski SW, Erasmus JJ, Petros WP, Vredenburgh JJ, Folz RJ. Delayed pulmonary toxicity syndrome following high-dose chemotherapy and bone marrow transplantation for breast cancer. Am J Respir Crit Care Med 1998; 157: $565-573$

24. O'Driscoll BR, Hasleton PS, Taylor PM, Poulter LW, Gattamaneni HR, Woodcock AA. Active lung fibrosis up to 17 years after chemotherapy with carmustine (BCNU) in childhood. N Engl J Med 1990; 323: 378-382.

25. Gurtner HP. Pulmonary hypertension, "plexogenic pulmonary arteriopathy" and the appetite depressant drug aminorex: post or propter? Bull Europ Physiopathol Respir 1979; 15: 897-923.

26. Voelkel NF. Appetite suppressants and pulmonary hypertension. Thorax 1997; 52: S63-S67.

27. Simonneau G, Fartoukh M, Sitbon O, Humbert M, Jagot JL, Herve P. Primary pulmonary hypertension associated with the use of fenfluramine derivatives. Chest 1998; 114 : 195S-199S.

28. Egermayer P. Epidemics of vascular toxicity and pulmonary hypertension: what can be learned? J Intern Med 2000; 247: 11-17.

29. Higenbottam TW. Bronchiolitis obliterans following the ingestion of an Asian shrub leaf. Thorax 1997; 52: S68S72.

30. Pfitzenmeyer P, Foucher P, Dennewald G, et al. Pleuropulmonary changes induced by ergoline drugs. Eur Respir J 1996; 9: 1013-1019.

31. Preuner JG, Lehle K, Keyser A, Merk J, Rupprecht L, Goebels R. Development of severe adverse effects after discontinuing amiodarone therapy in human heart transplant recipients. Transplant Proc 1998; 30: 39433944.

32. Chang CC, Petrelli M, Tomashefski JF, McCullough AJ. Severe intrahepatic cholestasis caused by amiodarone toxicity after withdrawal of the drug. A case report and review of the literature. Arch Pathol Lab Med 1999; 123: 251-256.

33. Camus P, Coudert B, d'Athis P, Dumas M, Escousse A, Jeannin L. Pharmacokinetics of amiodarone in the isolated rat lung. J Pharmacol Exp Ther 1990; 254: 336343.

34. Suhara T, Sudo Y, Yoshida K, et al. Lung as reservoir for antidepressants in pharmacokinetic drug interactions. Lancet 1998; 351: 332-335.

35. Amsterdam JD. Loeffler's syndrome: an uncommon adverse reaction to imipramine. Int $J$ Clin Psychopharmacol 1986; 1: 260-262.

36. Jessurun GAJ, Boermsa WG, Crijns HJGM. Amiodaroneinduced pulmonary toxicity. Predisposing factors, clinical symptoms and treatment. Drug Safety 1998; 18: 339-344.

37. Camus P, Lombard JN, Perrichon M, et al. Bronchiolitis obliterans organising pneumonia in patients taking acebutolol or amiodarone. Thorax 1989; 44: 711-715.

38. van Mieghem W, Coolen L, Malysse I, Lacquet LM, Deneffe GJD, Demedts MGP. Amiodarone and the development of ARDS after lung surgery. Chest 1994; 105: 1642-1645.

39. Aranda EA, Basanez RA, Jimenez YL. Bronchiolitis obliterans organising pneumonia secondary to amiodarone treatment. Neth J Med 1998; 53: 109-112.

40. Sitbon O, Bidel N, Dussopt C, et al. Minocycline pneumonitis and eosinophilia: a report on 8 patients. Arch Intern Med 1994; 154: 1633-1640.

41. Camus P, Reybet-Degat O, Justrabo E, Jeannin L. Dpenicillamine-induced severe pneumonitis. Chest 1982; 81: $376-378$

42. Ogata K, Koga T, Yagawa K. Interferon-related bronchiolitis obliterans organizing pneumonia. Chest 1994; 106: 612-613.

43. Vander Els NJ, Gerdes H. Sarcoidosis and IFN-alpha treatment. Chest 2000; 117: 294.

44. Liebhaber MI, Wright RS, Gelberg HJ, Dyer Z, Kupperman JL. Polymyalgia, hypersensitivity pneumonitis and other reactions in patients receiving HMG-CoA reductase inhibitors. Chest 1999; 115: 886-889.

45. Rubio C, Hill ME, Milan S, O'Brien MER, Cunningham D. Idiopathic pneumonia syndrome after high dose chemotherapy for relapsed Hodgkin's disease. $\mathrm{Br} J$ Cancer 1997; 75: 1044-1048.

46. Kantrow SP, Hackman RC, Boeckh M, Myerson D, Crawford SW. Idiopathic pneumonia syndrome Changing spectrum of lung injury after marrow transplantation. Transplantation 1997; 63: 1079-1086. 
47. Foucher P, Biour M, Blayac JP, et al. Drugs that may injure the respiratory system. Eur Respir J 1997; 10: 26527.

48. Pfitzenmeyer P, Foucher P, Piard F, et al. Nilutamide pneumonitis: a report on eight patients. Thorax 1992; 47: 622-627.

49. Voigt MD, Workman B, Lombard C, Kirsch RE. Halothane hepatitis in a South African population. Frequency and the influence of gender and ethnicity. S A Med J 1997; 87: 882-885.

50. Maruyama Y, Maruyama M, Takada T, Haraguchi M, Uno K. A case of pneumonitis due to Rikkunshi-to. Nippon Kyobu Shikkan Gakkai Zasshi 1994; 32: 84-89.

51. Oketani N, Saito H, Ebe T. Pneumonitis due to Hangeshashin-to. Nippon Kyobu Shikkan Gakkai Zasshi 1996; 34: 938-988.

52. De Smet PAGM. The role of plant-derived drugs and herbal medicines in healthcare. Drugs 1997; 54: 801-840.

53. Wu CL, Hsu WH, Chiang CD, et al. Lung injury related to consuming Sauropus androgynus vegetable. J Toxicol Clin Toxicol 1997; 35: 241-248.

54. Chang YL, Yao YT, Wang NS, Lee YC. Segmental necrosis of small bronchi after prolonged intakes of Sauropus androgynus in Taiwan. Am J Respir Crit Care Med 1998; 157: 594-598.

55. Ernst E. Harmless herbs? A review of the recent literature. Am J Med 1998; 104: 170-178.

56. Fenoglio JJ Jr, McAllister HA, Mullick FG. Drug-related myocarditis. I. Hypersensitivity myocarditis. Hum Pathol 1981; 12: 900-907.

57. Morrow PL, Hardin NJ, Bonadies J. Hypersensitivity myocarditis and hepatitis associated with imipramine and its metabolite desipramine. J Forensic Sci 1989; 34: 1016-1020.

58. Arima M, Kanoh T, Yamasaki A, et al. Eosinophilic myocarditis associated with toxicodermia caused by phenobarbital. Jpn Circulation J 1998; 62: 132-135.

59. Zaacks SM, Klein L, Tan CD, Rodriguez ER, Leikin JB. Hypersensitivity myocarditis associated with ephedra use. J Toxicol Clin Toxicol 1999; 37: 485-489.

60. Connolly HM, Crary JL, McGoon MD, et al. Valvular heart disease associated with fenfluramine-phentermine. N Engl J Med 1997; 337: 581-588.

61. Weissman NJ, Tighe JFJ, Gottdiener JS, Gwynee JT. An assessment of heart-valve abnormalities in obese patients taking dexfenfluramine, sustained-release dexfenfluramine, or placebo. $N$ Engl J Med 1998; 339: 725-732.

62. Jick H, Vasilakis C, Weinrauch L, Meier CR, Jick SS, Derby LE. A population-based study of appetite-suppressant drugs and the risk of cardiac-valve regurgitation. N Engl J Med 1998; 339: 719-724.

63. Hensrud DH, Connolly HM, Grogan M, Miller FA, Bailey KR, Jensen MD. Echocardiographic improvement overt time after cessation of use of fenfluramine and phentermine. Mayo Clin Proc 1999; 74: 1191-1197.

64. Anscher MS, Kong FM, Marks LB, Bentel GC, Jirtle RL. Changes in plasma transforming growth factor beta during radiotherapy and the risk of symptomatic radiation-induced pneumonitis. Int $J$ Radiation Oncol Biol Phys 1997; 37: 253-258.

65. Beaune PH, Lecoeur S. Immunotoxicology of the liver: adverse reactions to drugs. J Hepatol 1997; 26: 37-42. 